\title{
Effects of Meso-inositol Deficiency on Some Important Biological and Chemical Characteristics of Yeast
}

\author{
By L. M. LEWIN \\ Department of Biochemistry, Georgetown University, Schools of Medicine \\ and Dentistry, Washington, D.C. 20007, U.S.A.
}

(Received 16 April 1965)

\begin{abstract}
SUMMARY
Deficiency of meso-inositol (i-inositol, myo-inositol) caused decreased viability of Saccharomyces carlsbergensis ATCC 9080 and altered the internal morphology of the cells as seen in preparations stained with Nile Blue A, especially the nuclear membrane. Metabolic defects resulted which led to lipid accumulation in the organism and to increased concentrations of acetoin, acetaldehyde and glycerol in the culture medium. Hypotheses about the metabolic role of inositol are examined.
\end{abstract}

\section{INTRODUCTION}

Although meso-inositol (myo-inositol, i-inositol; in the sequel, inositol) is an essential nutrient factor for certain micro-organisms and some higher animals (mouse, rat, guinea pig, hamster, chick; Diem, 1962) and for human cells in tissue culture (Eagle, Oyama, Levy \& Freeman, 1957) it has not been associated with a metabolic function which completely explains its role. Since Eastcott (1928) first reported that inositol was required for the normal growth of a strain of yeast, several investigators have used various inositol-requiring yeast species to study inositol metabolism. Schopfer, Posternak \& Wustenfeld (1962) studied the effects of inositol deficiency and of administration of possible related anti-metabolites, with Schizosaccharomyces pombe, and observed marked changes in cellular morphology. They concluded that inositol functions as a regulator in cytogenesis and morphogenesis. Dawson, White \& Freinkel (1962) separated inositol monophosphate, inositol-containing lipids and an unidentified neutral derivative of inositol from Kloeckera brevis, an inositol-requiring yeast. Challinor \& Daniels (1955) and Challinor, Power \& Tonge (1964) reported that an inositol-deficient strain of Saccharomyces cerevisiae accumulated acetone-soluble lipids. $S$. carlsbergensis grown in a deficiency of inositol has been shown to grow in aggregates, as contrasted with the normal organisms, which grow singly or with a single bud (Smith, 1951). Ghosh, Charalampous, Sison \& Borer (1960) suggested that aggregation was due to a defective mechanism for synthesizing cell-wall material, since the walls of inositol-deficient yeasts were found to contain greater amounts of glucans than the walls of inositol-supplemented yeasts. In contrast with the work of Ridgway $\&$ Douglas (1958b), who utilized a different strain of $S$. carlsbergensis, Ghosh et al. (1960) reported that inositol-deficient yeasts retained their viability, exhibited a normal endogenous respiratory rate and were able to oxidize glucose, ethanol and acetate at normal rates. Ridgway \& Douglas $(1958 b)$ observed unbalanced growth 
of inositol-deficient yeasts, leading to death and accompanied by loss of cytochromes and nucleotide coenzymes. They suggested that the chief biochemical lesion involved the structure of a cytoplasmic granule, probably the mitochondrion (Ridgway \& Douglas, $1958 a, b)$. Since the above information has been obtained from observations on several different yeast species grown under differing conditions it seemed desirable to utilize one species in order to study the effects of inositol deficiency in detail. The work reported here is part of a study directed toward elucidating the biochemical functions of inositol in the inositol-requiring yeast strain, Saccharomyces carlsbergensis ATCC 9080. This organism is easy to grow on defined medium, shows dramatic inositol deficiency symptoms, has been well studied previously and has been used for the microbiological assay of inositol (Smith, 1951; McKibbin, 1959). The present report presents further data about the effects of inositol deficiency on the viability, growth rate, morphology, chemical composition and metabolic products of $\boldsymbol{S}$. carlsbergensis A'TCC 9080.

\section{METHODS}

Organism. Stock cultures of Saccharomyces carlsbergensis strain 4228 (ATCC no. 9080) were grown at $30^{\circ}$ for $48 \mathrm{hr}$ on Difco malt agar slopes and stored at refrigerator temperatures for 4-6 weeks. Samples ( $1 \mathrm{ml}$.) of a washed suspension of freshly grown $S$. carlsbergensis (Klett-Summerson colorimeter reading of 80-120 versus water blank; with no. 66 filter) were used to inoculate Erlenmeyer flasks (1 l.) containing $400 \mathrm{ml}$. of the inositol-assay medium of McKibbin (1959) modified by the omission of the casein hydrolysate and choline. Control flasks contained the above medium supplemented with inositol $5 \mathrm{mg}$./flask. Flasks were incubated at $28^{\circ}$ with shaking (New Brunswick Gyrotory Shaker) at about 145 oscillations/min. Samples of culture medium were periodically removed aseptically and used for turbidity readings, microscopic examination and chemical analyses.

Determination of growth rate and cellular viability. The growth rate of the organism was followed turbidimetrically by using a Klett-Summerson photoelectric colorimeter with filter no. $6 \theta$ and by direct microscopic count with a haemocytometer. The numbers of living and dead organisms were obtained by the methylene-blue vital staining technique of Fink \& Kuhles (1933), in which dead organisms stain blue while living organisms remain colourless. Viable cell counts were also made by plating suitable dilutions on malt agar (Difco).

Microscopic examination after staining with Nile Blue A. Normal and inositoldeficient organisms were stained with alkaline Nile Blue $A$ by the following modification of the method of Gancevici, Stoian \& Keller (1962). A drop of yeast suspension, previously washed with sterile saline, was placed on a microscope slide, mixed with 1 drop of glycine buffer (0.1 M; pH 10) and 1 drop of Nile Blue A solution (0.02\%), and then examined under a coverslip at about $\times 1000$ magnification. This technique clearly showed orange lipid inclusions, blue-green cytoplasm and a light purple nuclear compartment with 'dancing bodies'.

Lipid content of yeast organisms. Lipids were extracted from lyophilized yeast by the following modification of the method of Pedersen (1962). Samples of lyophilized yeast (about $1 \mathrm{~g}$.) were mixed to a paste with chloroform + methanol $(1+1$, by vol.) and ground with small glass beads in a mortar and pestle for $10 \mathrm{~min}$. 
More chloroform + methanol mixture $(10 \mathrm{ml}$.) was added, mixed, and the slurry filtered through a sintered-glass funnel (medium porosity). The extracted yeast was replaced in the mortar and the process repeated four times. Chloroform was added to adjust the extract to a composition of chloroform + methanol $2+1$ by vol. before washing with $\mathrm{MgCl}_{2}(0.0015 \mathrm{M})$ by the procedure of Folch, Lees \& Sloane-Stanley (1957). The washed lipid extract was evaporated to dryness and held in a desiccator to constant weight.

Total lipid was separated into phospholipid and non-phospholipid fractions on silicic acid as described by Hirsch (1963). These lipid fractions were then evaporated to dryness and brought to constant weight in a desiccator.

Composition of growth medium. Samples of deficient and inositol-supplemented culture fluids were removed from the corresponding yeast cultures periodically and were centrifuged to deposit the organisms. The supernatant broth fluids were measured by standard methods for $\mathrm{pH}$ value and for the concentrations of glycerol (Lambert \& Neish, 1956), acetoin (Westerfeld, 1945), acetaldehyde (method of Desnuelle \& Naudet, described by Neish, 1952), and glucose (by glucose oxidase method; Keston, 1956). The partial pressures of oxygen and carbon dioxide $\left(p \mathrm{O}_{2}\right.$ and $\left.p \mathrm{CO}_{2}\right)$ in Millipore-filtered liquid samples were determined using a blood gas analyser (Model 113, Instrumentation Laboratory, Inc., Boston, Mass., U.S.A.).

\section{RESULTS}

\section{Loss of cellular viability}

In our growth experiments, as in those of Smith (1951) and of Ghosh et al. (1960), it was observed that inositol-deficient organisms tended to grow in large aggregates. A vital staining method which would distinguish between living and dead organisms in a clump should therefore permit calculation of $\%$ viability and might provide information on the distribution of viable organisms within and among aggregates. For this purpose a vital staining technique based upon the staining of dead organisms by methylene blue was used to obtain the data of Table 1. Inositol deficiency apparently caused a distinct decrease in the viability of deficient organisms and the effect was annulled by the addition of inositol. Living and dead organisms were found to be distributed within the same aggregates. The number of dead organisms $/ \mathrm{ml}$. did not decrease after addition of inositol. The increase in $\%$ of viable organisms was therefore due to the production of many new viable organisms in the inositol-supplemented medium. Since methylene-blue staining has been reported to be a reliable indicator of viability only when the absolute viability of the culture is high (European Brewery Convention 1962) the viability of inositoldeficient and -supplemented cultures was also determined by plating suitable dilutions in malt agar. The results obtained were compared with those expected on the basis of the number of growth units/ml. observed by direct microscopic count. Cell aggregates and single cells each counted as one growth unit, since they would each lead to the formation of a single colony on a plate. These results (Table 2) also showed cellular death as a consequence of inositol deficiency. 
Table 1. The influence of inositol deficiency in the growth medium for Saccharomyces carlsbergensis ATCC 9080 on the viability and on dissolved oxygen and carbon dioxide in the culture

Samples were removed aseptically from the appropriate cultures at the times shown. Appropriate dilutions were prepared and viability was measured by the methylene-blue vital staining method of Fink \& Kuhles (1933). The partial pressures of oxygen and carbon dioxide in the culture fluid were measured using a blood gas analyser, as described in the text. After $71.5 \mathrm{hr}$ of incubation inositol $\left(5 \mathrm{mg}\right.$.) in $10 \mathrm{ml}$. sterile $\mathrm{H}_{2} \mathrm{O}$ was added to the inositol-deficient cultures and a blank consisting of sterile $\mathrm{H}_{2} \mathrm{O}(10 \mathrm{ml}$.) was added to the other cultures.

\begin{tabular}{|c|c|c|c|c|c|c|}
\hline $\begin{array}{c}\text { Time of } \\
\text { incubation }\end{array}$ & $\begin{array}{c}\text { Inositol } \\
+ \\
\text { Viab }\end{array}$ & $\begin{array}{c}\text { Inositol } \\
\overline{-} \\
y(\%)\end{array}$ & $\begin{array}{c}\text { Inositol } \\
+ \\
p \mathrm{O}_{2}\end{array}$ & $\begin{array}{c}\text { Inositol } \\
- \\
\mathbf{H g})\end{array}$ & $\begin{array}{c}\text { Inositol } \\
+{ }_{p \mathrm{CO}_{2}}\end{array}$ & $\begin{array}{c}\text { Inositol } \\
- \\
\mathbf{H g})\end{array}$ \\
\hline 0 & - & - & 158 & 150 & 11 & $<10$ \\
\hline 24 & - & -- & 80 & 128 & $>100$ & 58 \\
\hline 50 & 97 & 46 & - & 124 & $>10$ & $\mathbf{3 5}$ \\
\hline 71 & 94 & 10 & 142 & 158 & 15 & 15 \\
\hline \multicolumn{7}{|l|}{$\begin{array}{c}\text { Inositol } \\
\text { added }\end{array}$} \\
\hline 74 & - & 23 & - & - & - & -. \\
\hline 96 & 97 & 63 & $\ldots$ & $\ldots$ & - & $\ldots$ \\
\hline 133 & 98 & 78 & - & - & $\cdots$ & - \\
\hline
\end{tabular}

Table 2. The influence of inositol deficiency in the growth medium for Saccharomyces carlsbergensis ATCC 9080 on the viability of the organism, as determined by plate counting on malt agar

Samples were removed from inositol-deficient and -supplemented cultures at the times shown, diluted appropriately for direct microscopic counts (in a haemocytometer) of total cell count, methylene-blue viable count, and for count of growth units/ml. Samples were also removed, aseptically, diluted serially with sterile water, and plated into malt agar. Colonies were counted after $48 \mathrm{hr}$ of growth.

\begin{tabular}{|c|c|c|c|c|c|c|c|c|c|c|}
\hline \multirow{2}{*}{\multicolumn{2}{|c|}{$\begin{array}{c}\text { Inositol } \\
+\end{array}$}} & \multirow{2}{*}{$\begin{array}{c}\text { Inositol } \\
-\end{array}$} & \multirow{2}{*}{$\begin{array}{l}\text { Inositol } \\
+\end{array}$} & \multirow{2}{*}{$\begin{array}{c}\text { Inositol } \\
-\end{array}$} & \multicolumn{2}{|c|}{ Inositol } & \multicolumn{2}{|c|}{ Inositol } & \multicolumn{2}{|c|}{ Inositol } \\
\hline & & & & & + & - & + & - & + & - \\
\hline $\begin{array}{l}\text { Time of } \\
\text { incuba- } \\
\text { tion } \\
\text { (hr) }\end{array}$ & \multicolumn{2}{|c|}{$\begin{array}{cc}\text { of } & \text { Direct } \\
\text { microscopic } \\
\text { count } \\
\left(\text { cells } / \mathrm{ml}^{-1} 10^{-6} \times\right)\end{array}$} & \multicolumn{2}{|c|}{$\begin{array}{c}\text { Direct } \\
\text { microscopic } \\
\text { count } \\
\text { (growth units } / \mathrm{ml} \text {.) } \\
\left(10^{-6} \times\right)\end{array}$} & \multicolumn{2}{|c|}{$\begin{array}{c}\text { Plate count } \\
\text { (colonies/ml.) } \\
\left(10^{-6} \times\right)\end{array}$} & \multicolumn{2}{|c|}{$\begin{array}{l}\text { Viability } \\
\text { of growth } \\
\text { units }(\%)\end{array}$} & \multicolumn{2}{|c|}{$\begin{array}{l}\text { Viability } \\
\text { by methylene- } \\
\text { blue vital } \\
\text { stain }(\%)\end{array}$} \\
\hline 45 & 175 & 32 & 155 & $5 \cdot 0$ & 156 & 3.4 & 100 & 68 & 99 & 67 \\
\hline 68 & 167 & 46 & 136 & 6.7 & 132 & $\mathbf{3 \cdot 2}$ & 97 & 48 & 99 & $\mathbf{5 5}$ \\
\hline 93 & 171 & 53 & 143 & $7 \cdot 8$ & 130 & $1 \cdot 7$ & 91 & 22 & 99 & 48 \\
\hline
\end{tabular}

Decrease in growth rate

For short periods of growth (about $20 \mathrm{hr}$ ) a proportionality has previously been shown to exist between the concentrations of inositol (from 0 to $1 \mu \mathrm{g} . / \mathrm{ml}$.) and the rate of growth of Saccharomyces carlsbergensis ATCc 9080, and this property has led to its use as an inositol assay organism (Smith, 1951 ; McKibbin, 1959). With longer periods of incubation Smith (1951) reported that the inositol-deficient organisms grew to about the same crops as did inositol-supplemented organisms, presumably 
by slowly synthesizing some inositol. Our results of long period incubation (Fig. 1) show that inositol-deficient organisms eventually overtook normal organisms in total population as determined by turbidity and total counts. When cultures of inositol-deficient organisms were supplemented with inositol the growth rate increased rapidly (see Fig. 2) as the cells recovered from inositol deficiency.

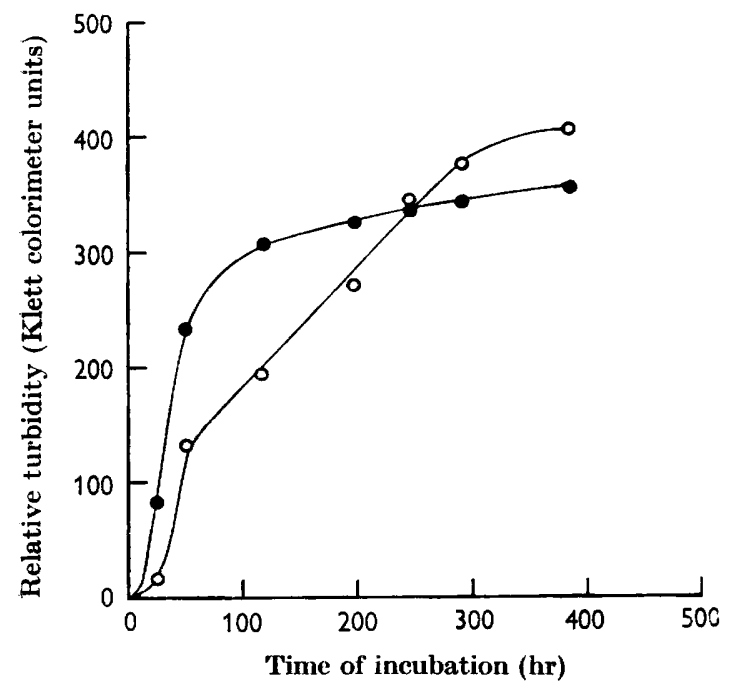

Fig. 1

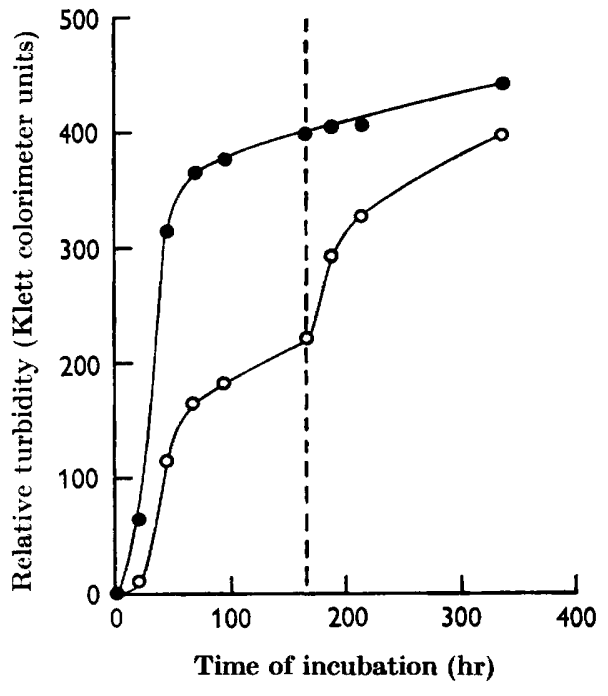

Fig. 2

Fig. 1. Growth of Saccharomyces carlsbergensis ATcc 9080 on media with and without inositol supplementation. 0 , Growth with added-inositol; $O$, growth without added inositol.

Fig. 2. The effect of adding inositol to Saccharomyces carlsbergensis ATcC 9080 growing in inositol-deficient medium. Turbidity of cultures grown on medium with inositol supplementation ( $5 \mathrm{mg} . / 400 \mathrm{ml}$.); $\bigcirc$, turbidity of cultures grown on medium to which inositol was added at the time shown by the vertical line $(167 \mathrm{hr})$.

\section{Changes in morphology}

The earliest visible alteration in the morphology of inositol-deficient Saccharomyces carlsbergensis ATCC 9080 was the formation of cellular aggregates. This phenomenon of aggregation was most pronounced early in growth. With very long periods of incubation (350-400 hr) the inositol-deficient cultures contained large numbers of single organisms or small aggregates, as well as some large aggregates. This disaggregation may reflect a spontaneous recovery of the organisms upon long incubation, since Smith (1951) reported that inositol-deficient organisms were capable of some slow synthesis of inositol.

After incubation for about $48 \mathrm{hr}$, microscopic examination of preparations stained with Nile Blue A showed some alteration of the internal structure. Following Lindegren's terminology (see Winge \& Roberts, 1958) the Nile Blue A-stained normal organisms after incubation for $75 \mathrm{hr}$ showed a structure containing a large, light-purple nucleus, surrounded by small orange-staining globules (possibly mitochondria) in blue-staining cytoplasm. The nucleus or nuclear vacuole was not apparent in inositol-deficient organisms, which contained intracellular granules and orange lipid globules in blue cytoplasm. After somewhat longer 
periods of incubation the cytoplasm of inositol-deficient organisms tended to lose its ability to retain blue and the orange lipid globules increased in size and fused to form large lipid droplets, similar to the lipid globules reported in Saccharomyces cerevisiae by Challinor \& Daniels (1955). Some inositol-deficient $S$. carlsbergensis ATCC 9080 organisms appeared to contain one or two spherical dark-purple inclusions.

After addition of inositol to the deficient growth medium some Saccharomyces carlsbergensis ATCC 9080 organisms continued to contain colourless cytoplasm and orange lipid globules and showed no signs of recovery. These were presumably the non-viable organisms whose presence was detected by the methylene-blue vital staining technique. Other organisms in the aggregates recovered their ability to stain blue, developed light-purple nuclei and began to bud. In some cases purple material was seen to connect an adjacent organism and a bud. Finally, newly formed buds apparently separated from the aggregates to form normal organisms, as described by Ghosh et al. (1960). After recovery for $24 \mathrm{hr}$ most of the viable organisms appeared as single or budding organisms, but there were still some aggregates present which contained both viable and dead organisms.

Inositol-deficient cultures tended to disaggregate after long periods (350-400 hr incubation). The resulting single organisms or small aggregates appeared to contain nuclei and blue cytoplasm and thus appeared to be more like normal organisms in their internal morphology than inositol-deficient organisms.

\section{Changes in composition of cells and growth medium}

The lipid material of normal and inositol-deficient cells was extracted and weighed (Table 3). Inositol-deficient organisms contained more lipid than did normal organisms. Fractionation on silicic acid indicated that the excess lipid from inositol-deficient organisms was mostly non-phospholipid.

\section{Table 3. Lipid content of normal and inositol-deficient Saccharomyces carlsbergensis ATCC 9080}

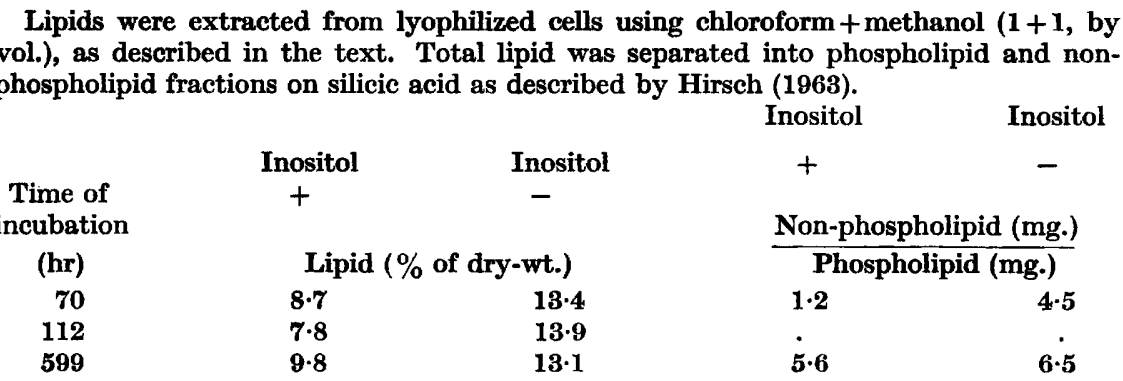

Analysis of the growth medium (Table 4) showed that inositol-supplemented organisms decreased the $\mathrm{pH}$ value of the culture more rapidly than did inositoldeficient organisms; but the final $\mathrm{pH}$ values were similar. During their period of rapid growth the normal organisms decreased the oxygen tension and increased the $\mathrm{CO}_{2}$ tension of the culture more dramatically than did the inositol-deficient cultures. Different products accumulated in the media during growth of normal and deficient organisms. We reported (Lewin \& Smith, 1964) the accumulation of acetoin by inositol-deficient cultures. Acetaldehyde, a precursor of acetoin in 
yeast, also accumulates (see Table 4). The results of experiments in which acetaldehyde was added to the growth medium at the start of incubation showed that inositol-deficient organisms were much more seriously inhibited by acetaldehyde than were normal organisms.

Table 4. The effect of inositol deficiency in the growth medium for Saccharomyces carlsbergensis a TCC 9080 on some metabolic products

\begin{tabular}{|c|c|c|c|c|c|c|}
\hline \multirow{2}{*}{$\begin{array}{c}\text { Time of } \\
\text { incubation } \\
\text { (hr) }\end{array}$} & $\begin{array}{c}\text { Inositol } \\
\pm\end{array}$ & $\begin{array}{c}\text { Inositol } \\
-\end{array}$ & $\begin{array}{c}\text { Inositol } \\
+\end{array}$ & $\begin{array}{c}\text { Inositol } \\
-\end{array}$ & $\begin{array}{c}\text { Inositol } \\
+\end{array}$ & $\begin{array}{c}\text { Inositol } \\
-\end{array}$ \\
\hline & \multicolumn{2}{|c|}{ pH value } & Acetoin & $(\mu \mathrm{mole} / \mathrm{ml})$. & Acetaldehyd & $(\mu \mathrm{mole} / \mathrm{ml})$. \\
\hline $\mathbf{0}$ & $4 \cdot 8$ & . & 0 & 0 & . & $\mathbf{0}$ \\
\hline 24 & $4 \cdot 4$ & $4 \cdot 7$ & $\mathbf{0}$ & $\mathbf{0}$ & $2 \cdot 1$ & $1 \cdot \mathbf{3}$ \\
\hline 44 & $4 \cdot 0$ & $4 \cdot 5$ & $2 \cdot 1$ & $1 \cdot 0$ & $4 \cdot 0$ & $7 \cdot 3$ \\
\hline 72 & $3 \cdot 8$ & $4 \cdot 3$ & $4 \cdot 7$ & $5 \cdot 7$ & $\mathbf{3 \cdot 9}$ & $10 \cdot 6$ \\
\hline 96 & $3 \cdot 9$ & $4 \cdot 2$ & $5 \cdot 8$ & $6 \cdot 2$ & $1 \cdot 7$ & $8 \cdot 0$ \\
\hline 192 & $\mathbf{3} \cdot \mathbf{9}$ & $\mathbf{3 . 9}$ & $4 \cdot 9$ & $13 \cdot 3$ & $1 \cdot 7$ & $8 \cdot 4$ \\
\hline 214 & $3 \cdot 9$ & $3 \cdot 8$ & $4 \cdot 1$ & $13 \cdot 7$ & $3 \cdot 9$ & $7 \cdot 6$ \\
\hline
\end{tabular}

Examination of the culture medium by paper chromatography indicated that there were several non-volatile compounds which reacted with alkaline silver nitrate reagent (Block, Durrum \& Zweig, 1958) which were present in higher concentrations in inositol-deficient cultures than in normal cultures. The most prominent of these spots was glycerol. Subsequent analyses for glycerol (method of Lambert \& Neish, 1950) showed that the inositol-deficient cultures accumulated up to four times as much glycerol as did the normal cultures (e.g. normal glycerol $=0.17 \mathrm{M}$; deficient $=0.07 \mathrm{M}$ after incubation for $428 \mathrm{hr}$ ). Three other silver nitratereducing materials were present to a greater extent in the inositol-deficient than in the normal cultures. Similar chromatograms were examined under ultraviolet radiation and were sprayed with the ninhydrin, $p$-anisidine $\mathrm{HCl}$ and aniline acid phthalate reagents described in Block et al. (1958) without giving evidence for the presence of additional compounds present differentially in normal and deficient cultures.

\section{DISCUSSION}

Whether inositol deprivation causes loss of cellular viability has been contested in the literature. Ridgway \& Douglas $(1958 b)$ reported that viable counts made by plating out suitable dilutions of Saccharomyces carlsbergensis on peptone yeast extract glucose agar indicated rapid loss of viability in inositol-deficient organisms. Ghosh et al. (1960), with $S$. carlsbergensis ATCC 9080, did not detect any evidence for cellular death caused by inositol deficiency. They noted that aggregation of inositol-deficient organisms complicated the interpretation of colony count data and therefore attempted to disrupt the aggregates by ultrasonic treatment before plating. This procedure, however, resulted in some disruption and death of organisms. On the basis of their data they stated that single organisms and aggregates 
of inositol-deficient organisms maintained their ability to form colonies on agar plates. The data presented here indicate that inositol-deficient $\boldsymbol{S}$. carlsbergensis ATCC 9080 suffered a definite loss in viability as measured by plating on to malt agar and by methylene-blue vital count. The difference between these conclusions and those of Ghosh et al. (1960) may be explained by noting that their viability determinations were made only on cultures grown for short times of incubation (up to $41 \mathrm{hr}$ ) when viability of inositol-deficient cultures might still be relatively high.

The data reported here confirmed the finding of Smith (1951) that the initial depression of the growth rate of inositol-deficient Saccharomyces carlsbergensis ATCC 9080 does not prevent the cultures from eventually reaching at least the same total population as that of inositol-supplemented organisms. Addition of inositol to the deficient organisms results in a rapid increase in the growth rate. The organisms newly formed upon recovery from inositol deficiency appear to separate from aggregates, as described by Ghosh et al. (1960) and appear to have normal internal morphology, as seen in preparations stained with Nile Blue A.

The internal structure of inositol-deficient Saccharomyces carlsbergensis ATCC 9080 appears to be deranged. Both the disappearance of the nuclear vacuole and the appearance of lipid globules in inositol-deficient organisms may be signs of damage to cellular membranes, since inositol phosphatides may play a role in their integrity.

The lipid material accumulated in inositol-deficient organisms was mostly nonphospholipid, in agreement with the results of Challinor \& Daniels (1955), who found that acetone-soluble lipids were accumulated by inositol-deficient Saccharomyces cerevisiae. Since lipids have also been reported to accumulate in inositol deficient Neurospora crassa (Shatkin \& Tatum, 1961) and since inositol has been reported to function as a lipotropic agent in higher animals (see discussion in Deuel, 1955), we shall later examine the lipids accumulated by inositol-deficient $S$. carlsbergensis ATcc 9080.

Since it appeared reasonable to assume that normal and inositol-deficient Saccharomyces carlsbergensis ATCC 9080 would differ in their rates of utilization of components of the growth medium and in the amount (and possibly in the nature) of the products excreted into the medium, an examination of the culture fluid might be expected to provide information about metabolic lesions in inositol deficiency; also, some of the visible signs of inositol deficiency might be caused by differences in the culture fluid medium which were secondary in nature. As reported previously (Lewin \& Smith, 1964), glucose utilization by inositol-deficient $S$. carlsbergensis ATCC 9080 cultures was slower than that of normal ones, but eventually all of the glucose in the medium was utilized. During their rapid growth and glucose utilization normal organisms decreased the $\mathrm{pH}$ values of the culture more rapidly than did inositol-deficient cells, but the final $\mathrm{pH}$ values were similar, indicating that about equal amounts of acid were produced. Larger amounts of acetoin, acetaldehyde and glycerol were found in cultures of inositol-deficient organisms than in normal organisms. From the products accumulated it would seem that inositol-deficient organisms were capable of forming hydroxyethylthiamine pyrophosphate (HETPP), which is a precursor of acetaldehyde, acetoin and acetyl-CoA. If the citric acid cycle were not functioning normally in inositoldeficient organisms one might expect more acetyl-CoA to be used for lipid synthesis 
and HETPP to be used to a greater extent than used for the formation of acetaldehyde and acetoin. It has long been known that acetaldehyde production in yeast fermentation may be correlated with the accumulation of glycerol therein (Nord, 1958). Abnormal function of the citric acid cycle might be expected to occur if the mitochondria were abnormal. Vignais, Vignais \& Lehninger (1964) showed that phosphatidylinositol is a specific compound essential for the contraction of aged mitochondria; Ridgway \& Douglas $(1958 a, b)$ suggested that inositol-deficient yeast have abnormal mitochondria.

A deficiency of inositol in the culture medium during aerobic incubation resulted in definite quantitative alterations in accumulation of metabolic products by Saccharomyces carlsbergensis ATCC 9080 . Since preliminary experiments have shown differences in morphology of organisms and composition of the culture media in anaerobically and aerobically grown inositol-deficient organisms, work is in progress designed to examine the results of inositol deficiency under anaerobic conditions. The inositol-deficiency symptoms (and particularly the accumulation of excess acetoin, acetaldehyde and glycerol) reported here may reflect the lack of inositol or a derivative of it which functions as a cofactor in some enzymic reaction(s). It is also possible that this accumulation of metabolic products may reflect the disorganization of intracellular structure which was seen by microscopic examination of the inositol-deficient organism.

This work was supported by the U.S. National Science Foundation Grant no. GB-2318 and by a grant from the Washington Heart Association. Thanks are due to Dr K. Moser and his staff for performing $p \mathrm{O}_{2}$ and $p \mathrm{CO}_{2}$ determinations and to Nathan Marcus and Jonathan Dehner for skilled technical assistance.

\section{REFERENCES}

Block, R. J., Durrum, E. L. \& Zweig, G. (1958). Manual of Paper Chromatography and Paper Electrophoresis, 2nd ed. New York: Academic Press.

Challinor, S. W. \& Daniels, N. W. R. (1955). Fat production by inositol-deficient yeast. Nature, Lond. 176, 1267.

Childinor, S. W., Power, D. M. \& Tonge, R. J. (1964). Effects of inositol-deficiency on yeast with particular reference to chemical composition of the cell and of the cell wall. Nature, Lond. 203, 250.

Dawson, R. M. C., White, R. W. \& Freinkel, N. (1962). The fate of meso-inositol during the growth of an inositol-dependent yeast Kloeckera brevis. J. gen. Microbiol. 57, 331.

Deuel, H. J. (1955). The Lipids, vol. 2, p. 675. New York: Interscience Publishers.

DiEm, K. (1962). Documenta Geigy, Scientific Tables, p. 470. New York: Geigy Corp., Ardsley.

Eagle, M., Oyama, V. I., Levy, M. \& Freeman, A. E. (1957). Myo-inositol as an essential growth factor for normal and malignant human cells in tissue culture. J. biol. Chem. 226, 191.

Eastcotr, E. V. (1928). Wildier's Bios. Isolation and identification of Bios I. J. Phys. Chem. 32, 1094.

European Brewery Convention: Yeast Group (1962). Estimation of yeast viability. J. inst. Brew., 68, 14.

Fink, H. \& Kunles, R. (1933). Beiträge zur Methylenblaufärbung der Hefezellen und Studien über die Permeabilität der Hefezellmembran. Z. Physiol. Chem. 218, 65.

Folch, J., Lees, M. \& Sloane-Stanley, G. H. (1957). A simple method for the isolation and purification of total lipids from animal tissues. J. biol. Chem. 226, 497. 
Gancevici, G., Stoian, I. \& Keller, Z. (1962). Localisation cytochimique des graisses dans les cultures de tissus. Archs. roum. Path. exp. Microbiol. 21, 191.

Ghosh, A., Charalampous, F., Sison, Y. \& Borer, R. (1960). Metabolic functions of myo-inositol. I. Cytological and chemical alterations in yeast resulting from inositol deficiency. J. biol. Chem. 235, 2522.

HirSCH, J. (1963). Factice chromatography. J. Lipid Res. 4, 1.

Keston, A. S. (1956). 129th Meeting American Chemical Society, Abstract of Paper, 31C.

LAAMBERT, M. \& NeISH, A. C. (1950). Rapid method for estimation of glycerol in fermentation solutions. Can. J. Res. B, $28,83$.

LEwIN, L. M., \& SMITH, E. J. (1964). Accumulation of acetoin by myo-inositol deficient yeast. Nature, Lond. 203, 867.

McKisBin, J. M. (1959). The determination of inositol, ethanolamine, and serine in lipids. Meth. biochem. Analysis, 7, 111.

Neish, A. C. (1952). Analytical Methods for Bacterial Fermentations, p. 37. Saskatoon: National Research Council of Canada.

Nord, F. F. \& Weiss, S. (1958). In A. H. Cook (ed.), Chemistry and Biology of Yeasts, p. 339. New York: Academic Press.

Pedersen, T. A. (1962). Lipid formation in Cryptococcus terricolus. III. Extraction and purification of lipids. Acta chem. scand. 16, 374.

RIDGway, G. J. \& Douglas, H. C. (1958 a). Distribution of inositol in subcellular fractions of yeast cells. J. Bact. 75, 85 .

Ridgway, G. J. \& Douglas, H. C. (1958b). Unbalanced growth of yeast due to inositol deficiency. J. Bact. 76, 163.

Schopfer, W. H., Posternak, T. \& Wustenfeld, D. (1962). Recherches sur le rôle du méso-inositol dans la biologie cellulaire de Schizosaccharomyces pombe Lindner. Arch. Microbiol. 44, 113.

Shatkin, A. J. \& Tatum, E. L. (1961). The relationship of m-inositol to morphology in Neurospora crassa. Am. J. Bot. 48, 760.

Smith, R. H. (1951). A study of the role of inositol in the nutrition of Nematospora gossypii and Saccharomyces carlsbergensis. J. gen. Microbiol. 5, 772.

Vignais, P. M., Vignais, P. V. \& Lehninger, A. L. (1964). Identification of phosphatidylinositol as a factor required in mitochondrial contraction. J. biol. Chem. 239, 2011.

Westerfexd, W. W. (1945). Colorimetric determination of blood acetoin. J. biol. Chem. $161,495$.

Winge, O., \& Roberts, C. (1958). In Chemistry and Biology of Yeasts (ed. by A. H. Cook), p. 111. New York: Academic Press. 